\title{
Impedance of flexible suction caissons
}

\author{
Morten Liingaard ${ }^{1, *, \dagger}$, Lars Andersen ${ }^{2}$ and Lars Bo Ibsen ${ }^{2}$ \\ ${ }^{1}$ DONG Energy, Kraftvaerksvej 53, Fredericia DK-7000, Denmark \\ ${ }^{2}$ Department of Civil Engineering, Aalborg University, Aalborg DK-9000, Denmark
}

\begin{abstract}
SUMMARY
The dynamic response of offshore wind turbines is affected by the properties of the foundation and the subsoil. The aim of this paper is to evaluate the dynamic soil-structure interaction of suction caissons for offshore wind turbines. The investigations include evaluation of the vertical and coupled sliding-rocking vibrations, influence of the foundation geometry and examination on the properties of the surrounding soil. The soil is simplified as a homogenous linear viscoelastic material and the dynamic stiffness of the suction caisson is expressed in terms of dimensionless frequency-dependent coefficients corresponding to different degrees of freedom. The dynamic stiffness coefficients for the skirted foundation are evaluated using a three-dimensional coupled boundary element/finite element model. Comparisons with known analytical and numerical solutions indicate that the static and dynamic behaviours of the foundation are predicted accurately using the applied model. The analysis has been carried out for different combinations of the skirt length, Poisson's ratio of the subsoil and the ratio of the soil stiffness to the skirt stiffness. Copyright (C) 2007 John Wiley \& Sons, Ltd.
\end{abstract}

Received 31 January 2006; Revised 4 June 2007; Accepted 18 June 2007

KEY WORDS: soil-structure interaction; boundary element method; dynamic stiffness; impedance; suction caisson; skirted foundation

\section{INTRODUCTION}

Wind turbines have increased tremendously in both size and performance during the last 25 years. The general output of the wind turbines is improved by larger rotors and more powerful generators. In order to reduce the costs, the overall weight of the wind turbine components is minimized, which means that the wind turbine structures become more flexible and thus more sensitive to dynamic excitation at low frequencies. The foundation principles for the recent major offshore wind farm projects in Europe have been dominated by two types of foundation solutions: the gravitational

*Correspondence to: Morten Liingaard, DONG Energy, Kraftvaerksvej 53, Fredericia DK-7000, Denmark.

†E-mail: molii@dongenergy.dk

Copyright (C) 2007 John Wiley \& Sons, Ltd. 


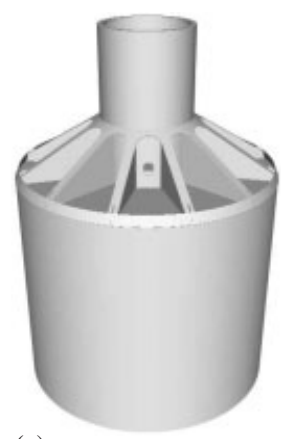

(a)

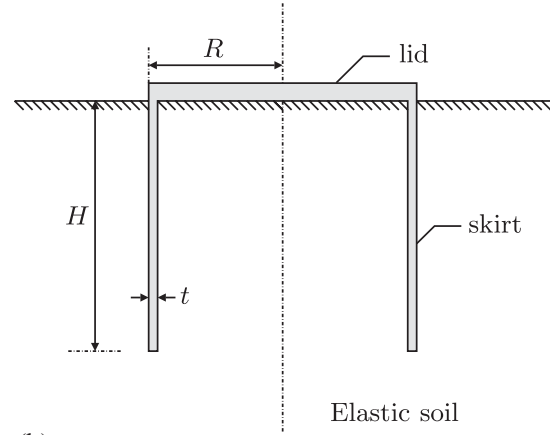

(b)

Figure 1. (a) Image and (b) geometry of the suction caisson.

foundation and the monopile. Recent research and development projects [1] have shown that suction caissons (see Figure 1) may be used as offshore wind turbine foundations in suitable soil conditions and water depths up to approximately $40 \mathrm{~m}$. Suction caissons (also denoted as bucket foundations or skirted foundations) have previously been used as anchors and foundations for several offshore platforms. Here, the suction caissons are mainly subjected to vertical and horizontal loads. On the other hand, when suction caissons are applied as monopod foundations for wind turbines, they must be able to sustain a significant overturning moment. At greater water depths, the monopod solution may become uneconomical and a foundation concept with three or four smaller suction caissons may become appropriate. The overturning moment is then stabilized by the opposing vertical reactions of the suction caissons, see [1,2]. The suction caisson is installed by using suction as the driving force and does not require a heavy installation equipment. Lowering the pressure in the cavity between the foundation and the soil surface causes a water flow to be generated, which again causes the effective stresses to be reduced around the tip of the skirt. Hence, the penetration resistance is reduced. A fully operational $3.0 \mathrm{MW}$ offshore wind turbine was installed on a prototype of the suction caisson foundation at the test field in Frederikshavn, Denmark in late 2002. The project is described in detail in $[3,4]$.

The aim of this paper is to evaluate the impedance of suction caisson foundations for offshore wind turbines, with the intention that the dynamic properties of the foundation can be properly included in a composite structure-foundation system. The frequency-dependent dynamic stiffness is evaluated using a dynamic three-dimensional coupled boundary element/finite element (BE/FE) program BEASTS by Andersen and Jones [5]. Initially, the solution methods for analysing soilstructure interaction are briefly introduced in Section 2. The method applied in this paper, i.e. the coupled BE/FE model, is described briefly in Section 3. The definitions of static and dynamic stiffness for the suction caisson are presented in Section 4. The results obtained by analysing the vertical and coupled sliding-rocking vibrations of the suction caisson are presented in Sections 5 and 6 , respectively. Note that the analysis with respect to torsional vibrations has been reported by Liingaard [4]. The main conclusions of the paper are given in Section 7. In this paper, the impedance is equal to the dynamic stiffness of the foundation, i.e. the impedance contains both a real and an imaginary part. 


\section{ANALYSIS METHODS FOR DYNAMIC SOIL-STRUCTURE INTERACTION}

The classical methods for analysing vibrations of foundations are based on analytical solutions for massless circular foundations resting on an elastic half-space. The classical solutions by Reissner, Quinlan and Sung were obtained by the integration of Lamb's solution for a vibrating point load on a half-space $[6,7]$. The mixed boundary value problems with prescribed conditions under the foundation and zero traction at the remaining free surface were investigated by Veletsos and Wei [8] and Luco and Westman [9]. The integral equations of the mixed boundary value problems were evaluated and tabulated for a number of excitation frequencies. A closed-form solution has been presented by Krenk and Schmidt [10].

Whereas analytical and semi-analytical solutions may be formulated for surface footings with a simple geometries, numerical analysis is required in the case of flexible embedded foundations with complex geometry. Thus, in the present analysis of suction caissons for offshore wind turbines, a coupled BE/FE model is applied. The finite element method (FEM) is very useful for the analysis of the structure with local inhomogeneities and complex geometries. However, only a finite region can be discretized. Hence, at the artificial boundaries of the unbounded domain, e.g. soil, transmitting boundary conditions must be applied as suggested by Higdon [11,12] and Krenk [13]. Numerous concepts, including the Scaled Boundary FEM, are presented by Wolf and Song [14], and Andersen [15] gave a brief overview of different solution techniques. However, in the present analysis, wave radiation into the subsoil is ensured by a coupling with the boundary element method (BEM). Since the full-space fundamental solution is utilized, both the soil-foundation interface and the free soil surface must be discretized. A smaller numerical model, i.e. a model with fewer degrees of freedom, may be obtained using of other types of solutions, e.g. half-space solutions. However, this comes at the cost that the fundamental solution can be very complicated, and often a closedform solution cannot be found. Furthermore, cavities in a half-space are known to give rise to spurious modes of vibration when the half-space solution is applied [16]. This is not the case for the full-space Green's function. The work within the BE formulation of dynamic soil-structure interaction has been reported by, for example, Domínguez [17] and Hall and Oliveto [18] and Beskos [19, 20].

\subsection{Previous work}

Veletsos and Tang [21] analysed the vertical vibrations of ring foundations, where the rigid circular surface footing is a special case. The analytical solution given by Veletsos and Tang is based on a perfect elastic half-space, and relaxed boundary conditions under the foundation are assumed. This work will be used as the reference solution for the subsequent analyses of the vertical vibrations.

Luco and Westmann [9] investigated the torsional vibrations of a circular massless footing resting on a homogeneous elastic half-space. They solved the system as a mixed boundary value problems with prescribed conditions under the foundation and zero traction at the remaining free surface. The integral equations of the mixed boundary value problems were evaluated and tabulated for a number of excitation frequencies. The effects of material damping on torsionally excited footings were reported by Veletsos and Damodaran Nair [22], while Wong and Luco [23] presented tables of horizontal, coupling, rocking, vertical and torsional impedance functions for rigid massless square foundations resting on layered viscoelastic soil. The impedance functions for rigid square foundations embedded in a uniform elastic half-space have been evaluated using a hybrid approach by Mita and Luco [24]. Emperador and Domínguez [25] applied the BEM for 
analysis of the dynamic response of axisymmetric embedded foundations. Approximate closedform solutions for the torsional impedance of circular embedded foundations have been reported by Novak and Sachs [26] and Avilés and Pérez-Rocha [27]. The coupled sliding-rocking vibrations of surface footings have been reported by Veletsos and Wei [8]. This work will be used as the reference solution for the subsequent analyses of the coupled sliding-rocking vibrations of the suction caissons. Bu and Lin [28] have summarized the work with respect to the analyses of coupled sliding-rocking vibrations of foundations and further references will not be repeated here.

\section{BOUNDARY ELEMENT/FINITE ELEMENT FORMULATION}

The dynamic stiffness of the suction caissons is evaluated using the dynamic three-dimensional coupled BEM/FEM program BEASTS by Andersen and Jones [5]. The BE part of BEASTS is an extension of the theory presented by Domínguez [17], which has been modified to account for open domains and to allow a coupling with finite elements, see [29] for details.

\subsection{Boundary elements for an open domain}

The wave propagation in the elastic domain $\Omega$ with the boundary $\Gamma$ is considered in the frequency domain. For each circular frequency, $\omega$, the fundamental solution, $U_{i l}^{*}(\mathbf{x}, \omega ; \boldsymbol{\xi})$, is applied as a weight function in the weak formulation of the equation of motion for the physical field, $U_{i}(\mathbf{x}, \omega)$, and vice versa. After some manipulations, and disregarding body forces in the interior of the domain, Somiglianas identity is derived as

$$
C_{i l}(\mathbf{x}) U_{l}(\mathbf{x}, \omega)+\int_{\Gamma} P_{i l}^{*}(\mathbf{x}, \omega ; \xi) U_{l}(\xi, \omega) \mathrm{d} \Gamma_{\xi}=\int_{\Gamma} U_{i l}^{*}(\mathbf{x}, \omega ; \xi) P_{l}(\xi, \omega) \mathrm{d} \Gamma \xi
$$

Here, $\mathbf{x}$ is an observation point, and $\xi$ is a source point. The notation $\mathrm{d} \Gamma_{\xi}$ indicates that the source point is applied as the integration variable. Furthermore, $P_{i l}^{*}(\mathbf{x}, \omega ; \xi)$ is the surface traction related to Green's function $U_{i l}^{*}(\mathbf{x}, \omega ; \xi) . C_{i l}(\mathbf{x})$ is a doubly indexed scalar that depends only on the geometry of the surface $\Gamma$. In particular, $C_{i l}(\mathbf{x})=1 / 2 \delta_{i l}$ on a smooth part of the boundary $\Gamma$ and $C_{i l}(\mathbf{x})=\delta_{i l}$ inside the body $\Omega$. A detailed derivation of (1) and the properties of $C_{i l}(\mathbf{x})$ are given in $[15,17]$.

In order to evaluate the boundary integral equations in (1) for a point $\mathbf{x}$ on the boundary, the surface is discretized into a finite number of boundary elements. The boundary integral equation can then be solved numerically for any point $\mathbf{x}$ on the boundary. In the present study, quadrilateral elements with quadratic interpolation are employed.

To obtain the BE formulation, the state variable fields on the boundary are discretized. Let $\mathbf{U}_{j}(\omega)$ and $\mathbf{P}_{j}(\omega)$ be the vectors storing the displacements and tractions at the $N_{j}$ nodes in element $j$. The displacement and traction fields over the element surface $\Gamma_{j}$ then become

$$
\mathbf{U}(\mathbf{x}, \omega)=\boldsymbol{\Phi}_{j}(\mathbf{x}) \mathbf{U}_{j}(\omega), \quad \mathbf{P}(\mathbf{x}, \omega)=\boldsymbol{\Phi}_{j}(\mathbf{x}) \mathbf{P}_{j}(\omega)
$$

where $\boldsymbol{\Phi}_{j}(\mathbf{x})$ is a matrix storing the interpolation, or shape, functions for the element. This allows the unknown values of the state variables to be taken outside the integrals in Equation (1). Finally, the three-row matrices originating from Equation (1) for each of the observation points may be assembled into a single matrix equation for the entire BE domain:

$$
\mathbf{H}(\omega) \mathbf{U}(\omega)=\mathbf{G}(\omega) \mathbf{P}(\omega)
$$


Component $(i, k)$ of the matrices $\mathbf{H}(\omega)$ and $\mathbf{G}(\omega)$ stores the influence from degree-of-freedom $k$ to degree-of-freedom $i$ for the traction and the displacement, respectively, i.e. the integral terms on the left- and right-hand side of Equation (1). The geometric constants $C_{i l}(\mathbf{x})$ are absorbed into the diagonal of $\mathbf{H}(\omega)$.

\subsection{Finite element $(F E)$ region}

The FE region of the model is formulated using the equation of motion in the frequency domain [30]:

$$
\left(-\mathbf{M} \omega^{2}+\mathrm{i} \mathbf{C}+\mathbf{K}\right) \mathbf{U}=\mathbf{K}_{\mathrm{FE}} \mathbf{U}=\mathbf{F}
$$

where $\mathbf{M}, \mathbf{C}$ and $\mathbf{K}$ are the mass, damping and stiffness matrices, respectively. $\mathbf{U}$ contains the nodal displacements and $\mathbf{F}$ the nodal forces. Hysteretic material damping is assumed, i.e. $\mathbf{C}=\eta \mathbf{K}$. Hence, the damping term is independent of the circular frequency $\omega$. Note that $\mathbf{K}_{\mathrm{FE}}=\left(-\mathbf{M} \omega^{2}+\mathbf{i} \mathbf{C}+\mathbf{K}\right)$ is a sparsely populated, banded and symmetric matrix.

\subsection{Coupling of FE and BE regions}

In the subsequent analysis, the foundation consists of relatively thin structures (skirt) and the use of boundary elements in this region is inappropriate due to the singularities of Green's functions. In these regions, finite elements are used. In order to couple a BE domain formulated in terms of surface tractions with an FE region with loads applied in terms of nodal forces, a transformation matrix $\mathbf{T}$ is defined, such that $\mathbf{F}=\mathbf{T P}$. Here, $\mathbf{F}$ is the vector of nodal forces equivalent to the tractions $\mathbf{P}$ applied on the surface of the domain. The transformation matrix depends only on the spatial interpolation functions, i.e. the shape functions, for the elements along the interaction boundary. Hence, $\mathbf{T}$ may be determined once and for all and applied in all analyses with a given model geometry. Subsequently, for each frequency the matrix

$$
\mathbf{T G}^{-1} \mathbf{H}=\mathbf{K}_{\mathrm{BE}}
$$

defines an equivalent dynamic stiffness matrix for the BE domain. The coupled FE/BE model utilized for the present analysis is based on a standard BE formulation. This implies that the dynamic stiffness matrices for the macro-finite elements $\left(\mathbf{K}_{\mathrm{BE}}\right)$ produced from the BE domains become nonsymmetrical and fully populated, which is a computational disadvantage in the coupling with the symmetric and sparse FE scheme. However, for a homogeneous half-space, a comparison with the semi-analytical solution by Sheng et al. [31] shows that the FE/BE model provides a very accurate solution, even with few elements per wavelength. Furthermore, Tullberg [32] concluded that the direct, original BE formulation provides higher accuracy than forced symmetric BE formulations. However, as an alternative a coupling of an FE shell model with the so-called symmetric Galerkin boundary-element method (SGBEM) may be applied [33]. An extensive review of the developments regarding the SGBEM can be found in the work by Ganguly et al. [34, 35].

\section{STATIC AND DYNAMIC STIFFNESS FORMULATION}

A generalized massless axisymmetric foundation with a rigid base has six degrees of freedom: one vertical, two horizontal, two rocking and one torsional. The six degrees of freedom and the 

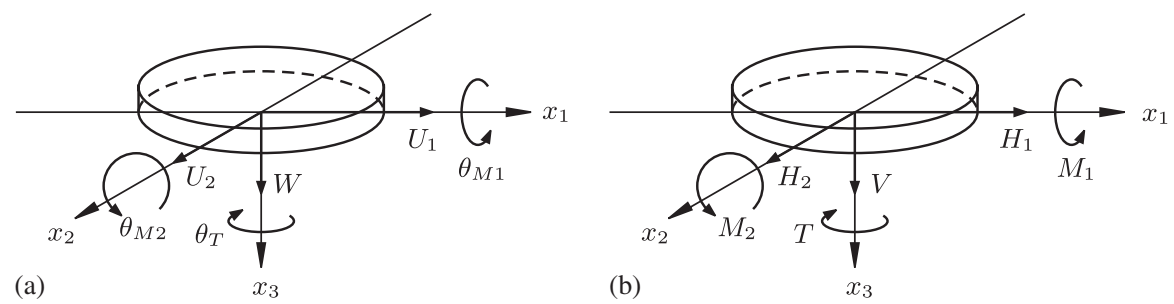

Figure 2. Degrees of freedom for a rigid surface footing: (a) displacements and rotations and (b) forces and moments.

corresponding forces and moments are shown in Figure 2. For a harmonic excitation with the cyclic frequency $\omega$, the dynamic stiffness matrix $\mathbf{S}$ is related to the vector of forces and moments $\mathbf{R}$ and the vector of displacements and rotations $\mathbf{U}$ as follows:

$$
\mathbf{R}=\mathbf{S U}
$$

The component form of Equation (6) can be written as

$$
\left[\begin{array}{c}
V / G_{\mathrm{s}} R^{2} \\
H_{1} / G_{\mathrm{s}} R^{2} \\
H_{2} / G_{\mathrm{s}} R^{2} \\
T / G_{\mathrm{s}} R^{3} \\
M_{1} / G_{\mathrm{s}} R^{3} \\
M_{2} / G_{\mathrm{s}} R^{3}
\end{array}\right]=\left[\begin{array}{cccccc}
S_{V V} & 0 & 0 & 0 & 0 & 0 \\
0 & S_{H H} & 0 & 0 & 0 & -S_{M H} \\
0 & 0 & S_{H H} & 0 & S_{M H} & 0 \\
0 & 0 & 0 & S_{T T} & 0 & 0 \\
0 & 0 & S_{M H} & 0 & S_{M M} & 0 \\
0 & -S_{M H} & 0 & 0 & 0 & S_{M M}
\end{array}\right]\left[\begin{array}{c}
W / R \\
U_{1} / R \\
U_{2} / R \\
\theta_{T} \\
\theta_{M 1} \\
\theta_{M 2}
\end{array}\right]
$$

where $R$ is the radius of the foundation and $G_{\mathrm{s}}$ is the shear modulus of the soil. The components in $\mathbf{S}$ are functions of the cyclic frequency $\omega$ and Poisson's ratio of the soil $v_{\mathrm{s}}$. The nonzero terms in $\mathbf{S}$ can be written as

$$
S_{i j}\left(a_{0}\right)=K_{i j}^{0}\left[k_{i j}\left(a_{0}\right)+\mathrm{i} a_{0} c_{i j}\left(a_{0}\right)\right], \quad(i, j=H, M, T, V)
$$

where $K_{i j}^{0}$ is the static value of $i j$ th stiffness component, whereas $k_{i j}$ and $c_{i j}$ are the dynamic stiffness and damping coefficients, respectively. Furthermore, $a_{0}=\omega R / c_{S}$ is the dimensionless frequency where $c_{S}$ is the shear wave velocity of the soil. The real part of Equation (8) is related to the stiffness and inertia properties of the soil-structure system, whereas the imaginary part describes the damping of the system. For a soil without material dissipation, $c_{i j}$ reflects the geometric damping, i.e. the radiation of waves into the subsoil.

In some situations, it is useful to examine the magnitude and phase angle of Equation (8) in addition to the real and imaginary parts of the dynamic stiffness. The magnitude (complex modulus) and the phase angle $\phi_{i j}$ of $S_{i j}$ are given by

$$
\left|S_{i j}\right|=K_{i j}^{0} \sqrt{\left(k_{i j}\right)^{2}+\left(a_{0} c_{i j}\right)^{2}}, \quad \phi_{i j}=\arctan \left(\frac{a_{0} c_{i j}}{k_{i j}}\right)
$$




\section{DYNAMIC STIFFNESS FOR VERTICAL VIBRATIONS}

In this section, the dynamic stiffness is investigated for several different combinations of the mechanical properties of the soil-foundation system. The first part of the section describes the modelling aspects of the BE/FE model applied in the analyses. Next, the static vertical stiffness obtained by the BE/FE model is presented and compared with results from a static FE analysis in ABAQUS [36]. The main part of the section presents the dynamic stiffness for vertical vibrations. In the first case, the flexibility of the soil-foundation system is investigated for different ratios between the soil and the foundation stiffness. The second case is the variation of the stiffness due to a change in the skirt length. Note that the vertical dynamic stiffness is relatively insensitive to variations in $v_{\mathrm{s}}$ in the range from 0.1 to 0.4 . However, when $v_{\mathrm{s}}$ approaches 0.5 , the dynamic behaviour changes significantly. The effects of Poisson's ratio on the stiffness are left out, see [4] for details. The first analysis is carried out for the frequency range $\left.\left.a_{0} \in\right] 0 ; 6\right]$, whereas the second analysis is extended to a larger frequency range $\left.\left.a_{0} \in\right] 0 ; 10\right]$. The purpose of the extension of the frequency range is to evaluate the asymptotic impedance behaviour in the high-frequency range. In the last subsection, the main findings are discussed.

\subsection{Boundary element/finite element model}

Due to symmetry only half the foundation is included. In the FE region, only half the model needs to be analysed when a plane of symmetry exists. The degrees of freedom in the plane of symmetry are simply eliminated in the system of equations in order to satisfy the conditions at the interface between the modelled and the non-modelled part. The procedure for introducing a plane of symmetry in the BE region is more complex and will not be given here. The procedure for $\mathrm{BE}$ analysis of problems with a geometrical symmetry is discussed in detail by Andersen and Jones [29].

The BE/FE model of the suction caisson consists of four sections: a massless FE section that forms the top of the foundation where the load is applied, an FE section of the skirts, a BE domain inside the skirts and, finally, a BE domain outside the skirts that also forms the free surface. The skirt of the suction caisson is considered flexible, and the lid is assumed to be rigid. The lid is modelled as a solid FE section with a thickness of $1 \mathrm{~m}$ to ensure rigidity compared with the flexible skirt. The lid thickness of $1 \mathrm{~m}$ has been used during all the analyses. Quadratic interpolation is employed. The models of the suction caisson and the subsoil contain approximately 100 finite elements and 350 boundary elements. The connection between the soil and the foundation corresponds to the condition of 'rough' contact since the foundation and the surrounding soil have common degrees of freedom. The model is illustrated in Figure 3.

The soil and the foundation are modelled as viscoelastic materials given by Poisson's ratio $v$, the mass density $\rho$ and a stiffness modulus (shear modulus $G$ or Young's modulus $E$ ). Material damping is introduced by a complex Young's modulus $E^{*}$, resulting in complex Lamé constants. The complex Young's modulus $E^{*}$ is given by

$$
E^{*}=E(1+\mathrm{i} \eta)
$$

where $\eta$ is the loss factor of the material and $i=\sqrt{-1}$ is the imaginary unit. Note that the loss factor is assumed to be constant for all frequencies, i.e. hysteretic damping is assumed.

The mesh of the free surface within the BE/FE model of the suction caisson is truncated at a distance of $30 \mathrm{~m}$ (six times radius $R$ ) from the centre of the foundation. The truncation distance 


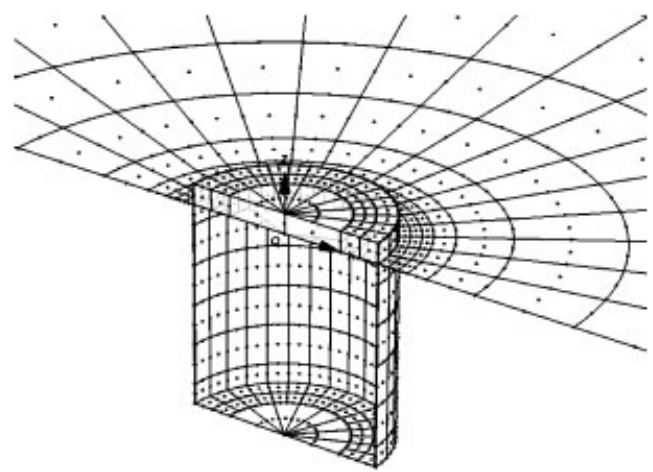

Figure 3. BE/FE model of the suction caisson.

for the models of the suction caisson depends on the skirt embedment. Convergence studies for the worst case $(H / D=2)$ suggested a truncation distance of $30 \mathrm{~m}$ from the centre of the foundation. This length has been used for all the BE/FE analyses of the suction caisson, regardless of embedment depth of the skirt. A dense mesh has been used at the interface between the skirt and the soil surface (node spacing of $0.25 \mathrm{~m}$ ) and a coarser mesh has been used from 10 to $30 \mathrm{~m}$ from the centre (node spacing of $1-3 \mathrm{~m}$ ). The mesh configuration is adequate for generating dynamic stiffness coefficients in the frequency range $\left.\left.a_{0} \in\right] 0 ; 10\right]$. Adaptive meshing [37] could possibly improve the accuracy versus the number of degrees of freedom, but this facility is currently not available in the BE/FE software.

For a given excitation frequency, a vertical load equal to $1 \mathrm{~N}$ is applied in the centre on top of the foundations and the complex displacements are computed. The complex vertical dynamic stiffness is then determined from the load and the displacement response. Note that the load control has been used for generating the stiffness values. Displacement control would be more appropriate, but this feature is currently not available in the BE/FE software. The suction caisson models contain approximately 3000 degrees of freedom and the runtime is approximately $30 \mathrm{~min}$ for each excitation frequency on a $2.0 \mathrm{GHz}$ P4 laptop computer.

\subsection{Static stiffness}

The vertical static stiffness $K_{V V}^{0}$ corresponds to the stiffness of the soil-foundation system without any inertial or material dissipation effects. The vertical static stiffness coefficient has been determined using a static FE analysis in ABAQUS. These static results have been used as convergence criteria for the element mesh size in the subsequent BE analyses of the dynamic stiffness. The reason for using the static stiffness as convergence criteria is that the shape of the impedance (location of peaks as a function of frequency) converges with a relatively coarse mesh, compared with the actual magnitude of the impedance. Surprisingly, it turns out that the magnitude of the impedance is the critical convergence parameter. The static stiffness from the FE/BE models is estimated for a very low excitation frequency, $a_{0}=0.01$, where the inertial effects are negligible.

The static three-dimensional FE model of the suction caisson consists of a foundation and nearfield soil domain modelled by second-order finite elements and a far-field soil domain modelled by infinite elements. The skirt of the suction caisson is flexible, considering the fact that the skirt 
Table I. Vertical static stiffness.

\begin{tabular}{lrrc}
\hline & $K_{V V}^{0} \mathrm{FE}$ & $K_{V V}^{0} \mathrm{FE} / \mathrm{BE}$ & Deviation (\%) \\
\hline$H / D$ & & & \\
$1 / 4$ & 7.25 & 7.39 & -1.88 \\
1 & 10.70 & 10.87 & -1.60 \\
2 & 14.61 & 14.99 & -2.53 \\
$G_{\mathrm{S}}(\mathrm{Pa})$ & & & \\
$10^{5}$ & 10.73 & 10.91 & -1.65 \\
$10^{6}$ & 10.70 & 10.87 & -1.60 \\
$10^{7}$ & 10.65 & 10.48 & +1.58 \\
$10^{8}$ & 10.03 & 10.19 & -1.62 \\
$10^{9}$ & 7.85 & 8.01 & -2.03 \\
\hline
\end{tabular}

thickness is small compared with the height or diameter of the foundation. The lid is assumed to be rigid. The lid is modelled as a solid FE section with a thickness of $1 \mathrm{~m}$ and the same material properties as the skirt. The static FE model contains approximately 200000 degrees of freedom and the runtime is approximately $1 \mathrm{~h}$ per stiffness coefficient on a $2.0 \mathrm{GHz}$ P4 laptop computer. The non-dimensional values of $K_{V V}^{0}$ are given for two different cases.

Different skirt lengths: The static stiffness $K_{V V}^{0}$ is given for various ratios between the foundation diameter $D$ and the length of the skirt $H$ in Table I. The soil properties are $G_{\mathrm{s}}=1 \mathrm{MPa}$ and $v_{\mathrm{s}}=1 / 3$.

Varying soil stiffness: $K_{V V}^{0}$ is given for different values of the shear modulus $G_{\mathrm{s}}$ in the soil in Table I. $H / D=1$ and $v_{\mathrm{s}}$ is $1 / 3$.

The data are shown for fixed material properties of the foundation $\left(E_{\mathrm{f}}=210 \mathrm{GPa}, v_{\mathrm{f}}=0.25\right)$. The foundation radius is $R=5 \mathrm{~m}$ and the skirt thickness is $t=50 \mathrm{~mm}$.

In general, there is a good agreement between the values of $K_{V V}^{0}$ computed by $\mathrm{FE}$ and BE/FE when it is taken into account that $K_{V V}^{0}$ has been calculated using two different methods of analysis and discretization. The two numerical models provide similar results, indicating that both the ABAQUS and the BEASTS models are nearly converged. The deviation is properly due to the fact that better convergence has been obtained by the FE solution. There is a tendency of increasing deviations with increasing skirt lengths. It should be noted that the static vertical stiffness for low values of $G_{\mathrm{s}}(0.1$ and $1.0 \mathrm{MPa})$ is equivalent to the stiffness of a suction caisson with rigid skirts, whereas high values of $G_{\mathrm{s}}$ (approaching the shear modulus of the skirts) correspond to the behaviour of a rigid base surface foundation. The results agree with the work by Doherty and Deeks [38] and Doherty et al. [39], who employed the scaled boundary FE method to analyse the static stiffness of suction caissons embedded in non-homogeneous elastic soil.

\subsection{Dynamic stiffness-variation in the soil stiffness}

The influence on the ratio of the stiffness of the soil to the stiffness of the structure is evident from the analysis of the static stiffness, see Table I. The influence on the dynamic behaviour is shown in Figure 4 for the frequency range $\left.\left.a_{0} \in\right] 0 ; 6\right]$. The fixed model properties are $H / D=1$, $v_{\mathrm{s}}=1 / 3, \rho_{\mathrm{s}}=1000 \mathrm{~kg} / \mathrm{m}^{3}, \eta_{\mathrm{s}}=5 \%, E_{\mathrm{f}}=210 \mathrm{GPa}, v_{\mathrm{f}}=0.25, \eta_{\mathrm{f}}=2 \%$ and $t=50 \mathrm{~mm}$. To model a massless foundation $\rho_{\mathrm{f}}=0$ for the lid of the caisson and $\rho_{\mathrm{f}}=\rho_{\mathrm{s}}$ for the skirt. 

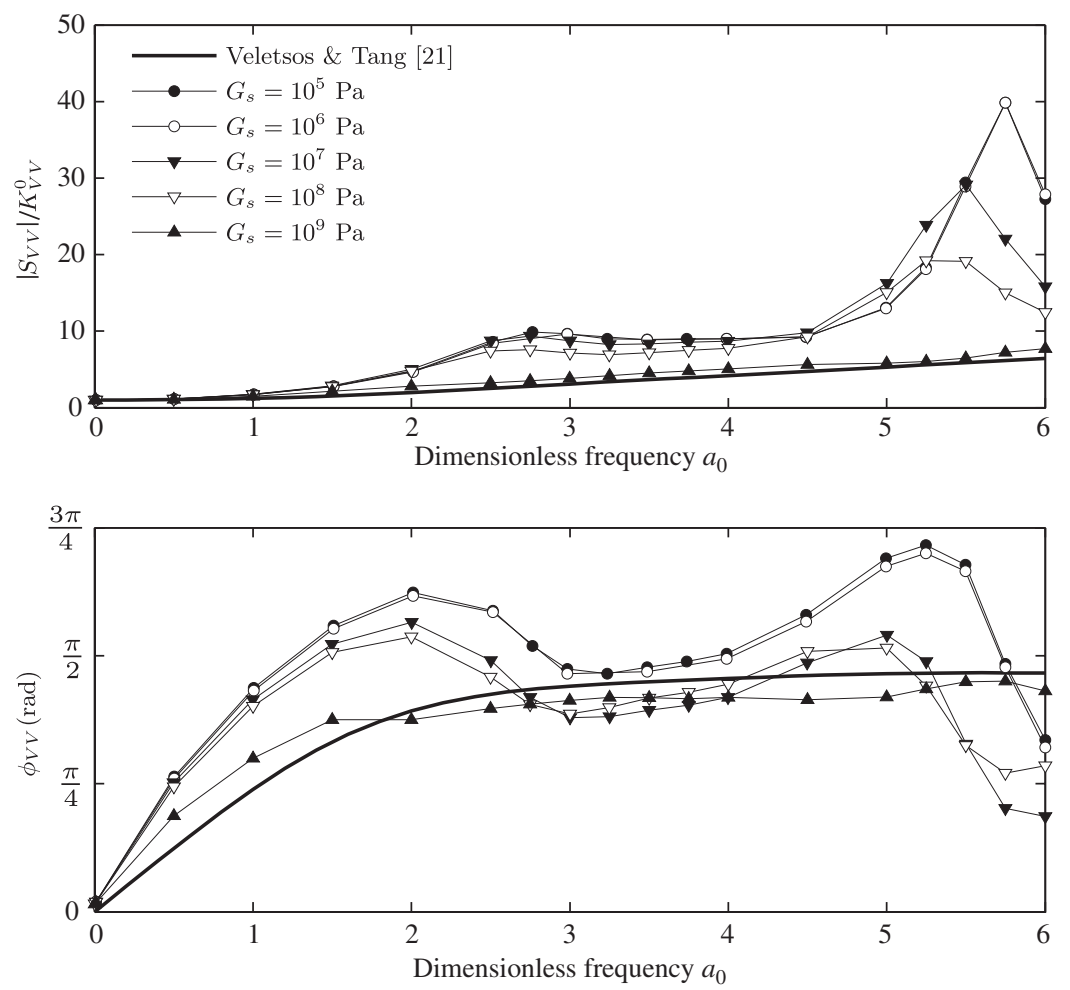

Figure 4. Vertical dynamic stiffness: variation in the soil stiffness. $H / D=1, v_{\mathrm{s}}=\frac{1}{3}$ and $\eta_{\mathrm{s}}=5 \%$.

The shape of the curve for high values of $G_{\mathrm{S}}(1000 \mathrm{MPa})$ approaches the shape of the frequencydependent behaviour of the surface foundation. When $G_{\mathrm{s}}$ decreases, the local oscillations become more distinct and the influence of the skirt flexibility vanishes, i.e. the caisson reacts as a rigid foundation. Rigid behaviour can be assumed for $G_{\mathrm{s}} \leqslant 1.0 \mathrm{MPa}$.

\subsection{Dynamic stiffness-variation in the skirt length}

The variation of the dynamic stiffness due to a change in the skirt length $H$ is presented in the following. The BE/FE models for the analysis are similar to the model shown in Figure 3 . The model properties are $G_{\mathrm{s}}=1 \mathrm{MPa}, v_{\mathrm{s}}=1 / 3, \rho_{\mathrm{s}}=1000 \mathrm{~kg} / \mathrm{m}^{3}, \eta_{\mathrm{s}}=5 \%, E_{\mathrm{f}}=210 \mathrm{GPa}, v_{\mathrm{f}}=0.25$, $\eta_{\mathrm{f}}=2 \%$ and $t=50 \mathrm{~mm}$. Note that $\rho_{\mathrm{f}}=0$ for the lid of the caisson and $\rho_{\mathrm{f}}=\rho_{\mathrm{s}}$ for the skirt. In order to get a picture of the high-frequency behaviour of the suction caisson, the analyses have been performed for the frequency range $\left.\left.a_{0} \in\right] 0 ; 12\right]$. A comparison is made with the vertical dynamic stiffness for a surface footing. The analytical solution by Veletsos and Tang used as a reference in the previous subsection is not available for $\left.\left.a_{0} \in\right] 0 ; 12\right]$. Consequently, the reference result has been obtained using of a three-dimensional BE/FE model with no skirt, i.e. with $H=0$. The components of the vertical dynamic stiffness for the surface footing, $H / D=1 / 4,1$ and 2 , are shown in Figure 5. 

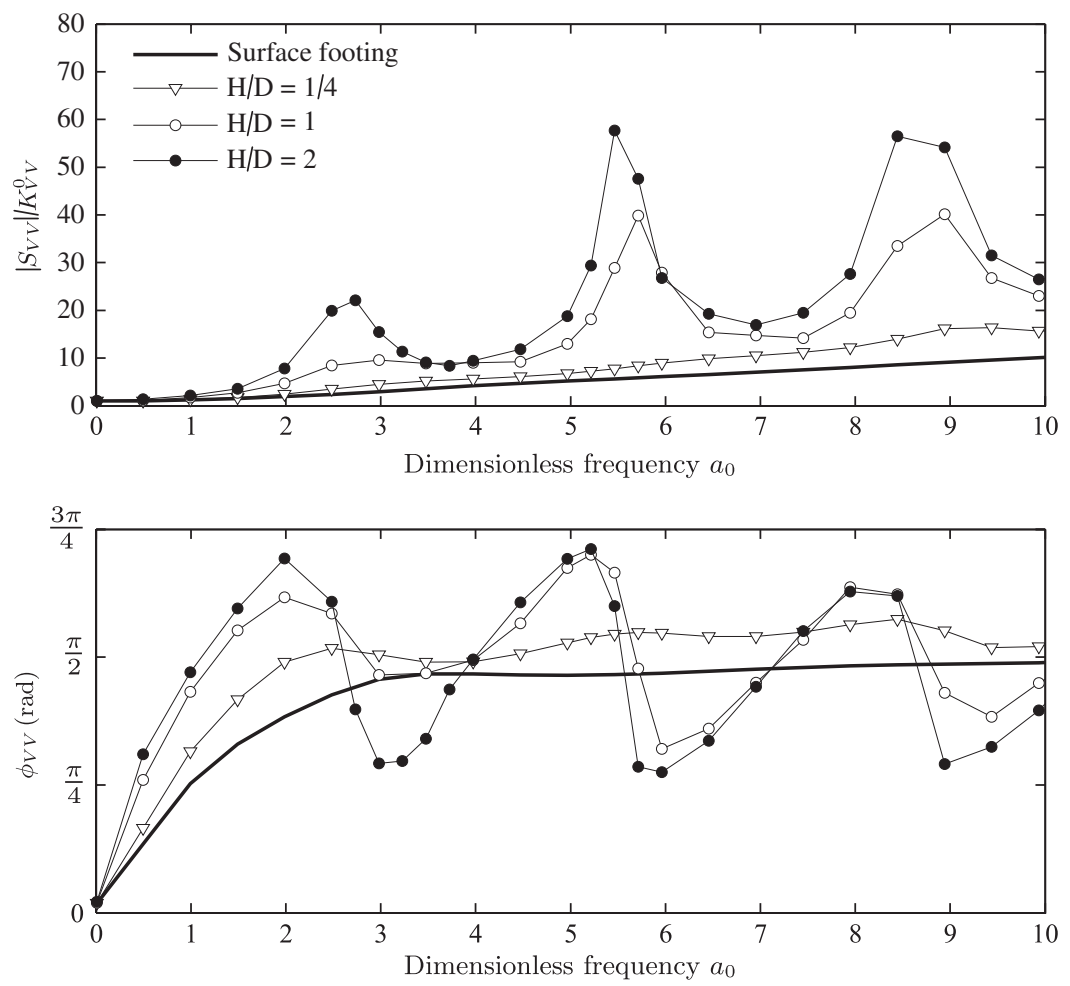

Figure 5. Vertical dynamic stiffness: high-frequency behaviour. $G_{\mathrm{s}}=1.0 \mathrm{MPa}, v_{\mathrm{s}}=\frac{1}{3}$ and $\eta_{\mathrm{s}}=5 \%$.

The vertical dynamic stiffness of the caisson with a relatively small embedment depth $(H / D=$ 1/4) varies smoothly with the frequency, whereas the magnitude for $H / D=1$ and 2 is characterized by distinct peaks, and it can be observed that the magnitude of the dynamic stiffness overall increases with the skirt length.

\subsection{Discussion}

There are several observations associated with the oscillations of the impedance of the suction caissons:

- The peaks of the normalized magnitude are located at phase angles equal to $\pi / 2$.

- The distance between the peaks is approximately $\Delta a_{0}=3.0-3.5$.

- The amplitude of the peaks increases significantly with the skirt length.

However, the appearance of distinct peaks in the magnitude of the stiffness around certain frequencies cannot be explained by the variation in the skirt length, Poisson's ratio and the flexibility of the skirt. The fact that the oscillations are repeated for equal distances in frequency suggests that the phenomenon is due to wave interference in the soil inside the suction caisson. Since the amplitude of the peaks significantly increases with the skirt length, it seems reasonable to examine the axial impedance of an infinite cylinder, in order to study the wave interference inside the caisson. 

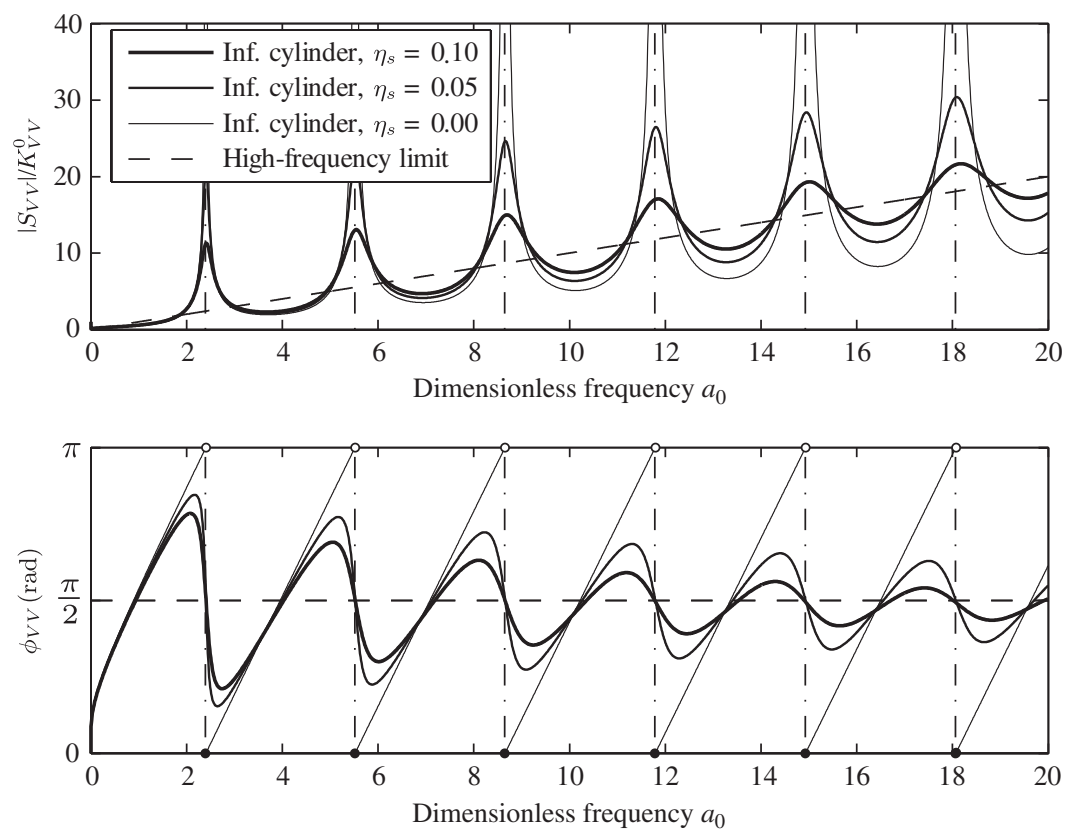

Figure 6. Solution to an infinite cylinder subjected to dynamic vertical excitation in the axial direction.

The dynamic stiffness per unit length of an infinite cylinder subjected to a dynamic vertical excitation in the axial direction is shown in Figure 6. The dynamic stiffness is computed for $\eta_{\mathrm{s}}=0.00,0.05$ and 0.10 , and the data are represented by the normalized magnitude and the phase angle. The slope of the dashed line in Figure 6 is equal to the limiting damping parameter unit length of the infinite cylinder. The limiting damping parameter describes the impedance for $a_{0} \rightarrow \infty$ (see [4] for details). Note that the vertical motion of the infinitely long cylinder generates only $S$-waves, i.e. there is no contribution of $P$-waves. The solution to the impedance of the infinite cylinder subjected to dynamic vertical excitation in the axial direction is given in [4].

The similarities of the impedance in Figures 5 and 6 are remarkable. However, the normalized magnitudes are not to scale, but the patterns of the magnitude and the phase angle of the suction caissons $(H \geqslant 1)$ are equivalent to those of the infinite cylinder for $\eta_{\mathrm{s}}=0.05$. The closed-form solution to the vertical dynamic stiffness $S_{V V}(\omega)$ of the infinite cylinder is given by

$$
S_{V V}(\omega)=\frac{K_{V V}^{0}}{R J_{0}\left(k_{S} R\right) K_{0}\left(\mathrm{i} k_{S} R\right)}, \quad K_{V V}^{0}=2 \pi R G_{\mathrm{s}}
$$

where $J_{0}$ is the Bessel function of the first kind and order $0, K_{0}$ is the modified Bessel function of the second kind and order 0 , whereas $k_{S}=\omega / c_{S}$ is the wavenumber of $S$-waves. Recall that $G_{\mathrm{s}}$ is the shear modulus of the soil. As reported by Kitahara [40], $J_{0}\left(k_{S} R\right)$ has a number of zeros for $\eta_{\mathrm{s}}=0$ and $k_{S}>0$. At the corresponding cyclic frequencies, $S_{V V}(\omega)$ becomes singular and the stiffness becomes infinite. These anti-resonance frequencies are marked in Figure 6 by the vertical lines with the dash-dot signature. The distance between the lines tends towards $\pi$ for $\omega \rightarrow \infty$. 
Thus, the $n$th anti-resonance mode occurs at the non-dimensional frequency $a_{0} \rightarrow \pi(n-1 / 4)$ for $n \rightarrow \infty$.

\section{DYNAMIC STIFFNESS FOR COUPLED SLIDING-ROCKING VIBRATIONS}

In this section, the coupled sliding-rocking vibrations are investigated for several different combinations of the mechanical properties of the soil-foundation system. The first case concerns the effects of Poisson's ratio on the stiffness. The second analysis investigates the variation of the stiffness due to a change in the skirt length.

\subsection{Boundary element/finite element model}

The geometry and the discretization in the BE/FE models employed for the present analyses are as described in the previous sections. However, the load is applied differently. For a given excitation frequency, two analyses are performed: one analysis with horizontal loading at the base of the lid of the caisson, and another analysis with a set of opposing vertical forces that are applied at each side of the foundation in order to create a rocking moment. The first analysis provides a relation between the horizontal force and the resulting displacements and rotations. The second analysis relates the applied moment to the resulting displacements and rotations. The system can be written as a subset of Equation (7), given as

$$
\left[\begin{array}{c}
H_{1} / G_{\mathrm{s}} R^{2} \\
M_{2} / G_{\mathrm{s}} R^{3}
\end{array}\right]=\left[\begin{array}{cc}
S_{H H} & -S_{H M} \\
-S_{M H} & S_{M M}
\end{array}\right]\left[\begin{array}{c}
U_{1} / R \\
\theta_{M 2}
\end{array}\right]
$$

The two equations are then solved simultaneously, in order obtain the complex horizontal sliding impedance, $S_{H H}$, the rocking moment impedance, $S_{M M}$, and the coupling impedances, $S_{H M}$ and $S_{M H}$. As already mentioned and further discussed below, $S_{H M}=S_{M H}$ within the precision of the model.

\subsection{Static stiffness}

The static stiffness coefficients of the coupled system have been determined using the BE/FE models for $a_{0}=0.01$, and then compared with the results of static FE analyses. The non-dimensional values of $K_{H H}^{0}, K_{M M}^{0}, K_{H M}^{0}$ and $K_{M H}^{0}$ are given for two different cases.

Different skirt lengths: The static stiffness components are given for various ratios between the foundation diameter $D$ and the length of the skirt $H$ in Table II. The soil properties are $G_{\mathrm{s}}=1 \mathrm{MPa}$ and $v_{\mathrm{S}}=1 / 3$.

Different Poisson's ratios: The variation in the static stiffness with respect to Poisson's ratio is shown in Table II. $H / D=1$ and $G_{\mathrm{s}}=1 \mathrm{MPa}$.

Note that the values in parentheses in Table II are obtained using the static FE analyses in ABAQUS. The data are shown for fixed material properties of the foundation $\left(E_{\mathrm{f}}=210 \mathrm{GPa}\right.$, $v_{\mathrm{f}}=0.25$ ). The foundation radius is $R=5 \mathrm{~m}$ and the skirt thickness is $t=50 \mathrm{~mm}$. In addition to the analyses listed above, it may be relevant to check the influence of the skirt flexibility. However, a preliminary study indicates that changes in $E_{\mathrm{f}}$ and $t$ within the range that is relevant for suction caissons have little impact on the overall performance of the foundation compared with the skirt 
length and Poisson's ratio of the ground. Therefore, this study will not be included in the present analysis.

The largest deviations between the results from the BE/FE model and the ABAQUS models in Table II are: 7.4,7.2 and $16.8 \%$ for the sliding, rocking and coupling term, respectively.

Table II. Coupled static stiffness.

\begin{tabular}{lrrrrrrrr}
\hline & \multicolumn{2}{c}{$K_{H H}^{0}$} & \multicolumn{2}{c}{$K_{M M}^{0}$} & \multicolumn{2}{c}{$K_{H M}^{0}$} & \multicolumn{2}{c}{$K_{M H}^{0}$} \\
\hline$H / D$ & & & & & & & & \\
$1 / 4$ & 8.00 & $(7.47)$ & 8.51 & $(8.41)$ & -3.13 & $(-2.68)$ & -2.78 & $(-2.68)$ \\
1 & 13.92 & $(12.98)$ & 52.91 & $(49.73)$ & -18.28 & $(-16.11)$ & -17.20 & $(-16.12)$ \\
2 & 18.61 & $(18.47)$ & 198.87 & $(193.41)$ & -44.80 & $(-43.02)$ & -43.54 & $(-43.12)$ \\
$v_{s}$ & & & & & & & & \\
0.1 & 12.49 & $(11.62)$ & 49.75 & $(46.91)$ & -17.11 & $(-15.19)$ & -16.09 & $(-15.21)$ \\
0.2 & 13.01 & $(12.14)$ & 50.83 & $(47.92)$ & -17.50 & $(-15.53)$ & -16.47 & $(-15.55)$ \\
0.333 & 13.92 & $(12.98)$ & 52.91 & $(49.73)$ & -18.28 & $(-16.11)$ & -17.20 & $(-16.12)$ \\
0.4 & 14.54 & $(13.53)$ & 54.42 & $(51.02)$ & -18.86 & $(-16.54)$ & -17.75 & $(-16.53)$ \\
0.495 & 15.74 & $(14.51)$ & 57.79 & $(53.98)$ & -20.19 & $(-17.42)$ & -18.95 & $(-17.39)$ \\
\hline
\end{tabular}
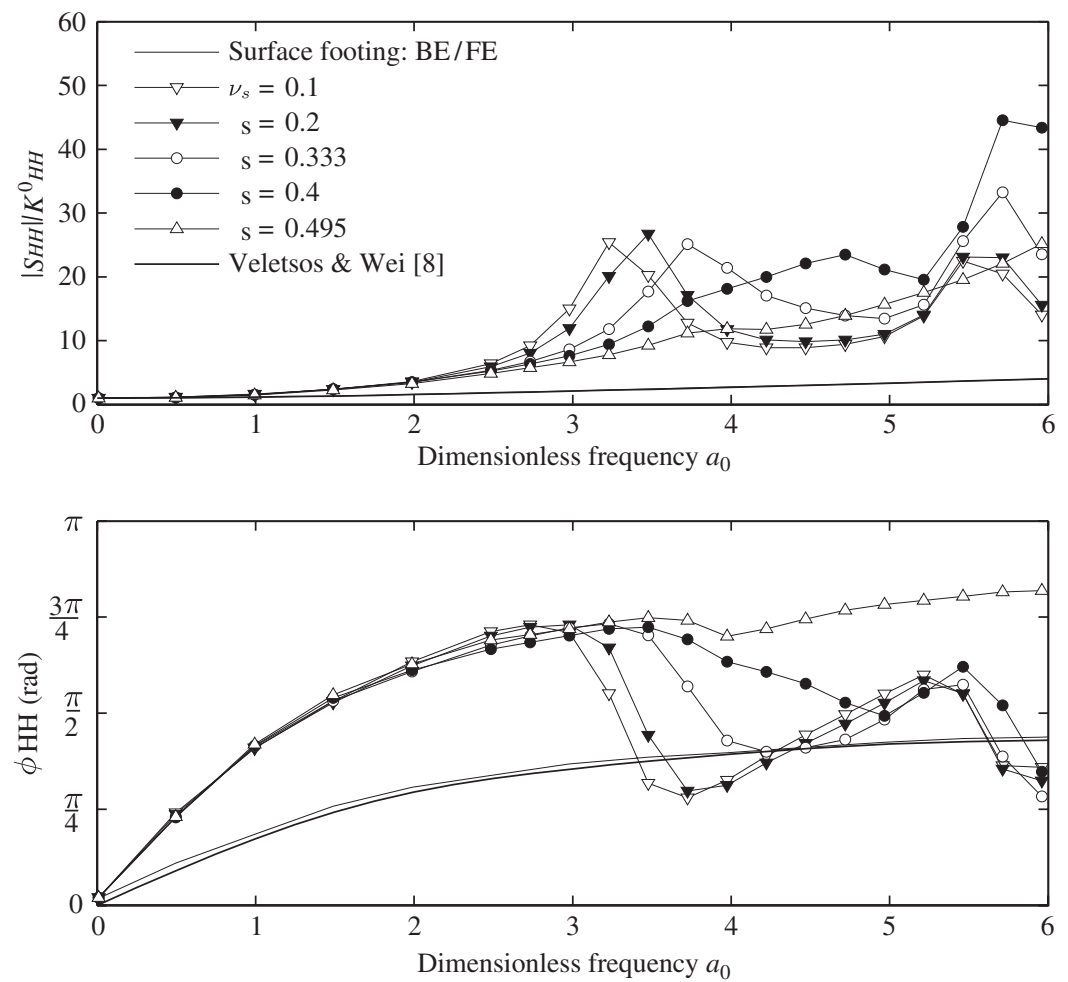

Figure 7. Sliding impedance: variation in Poisson's ratio. $G_{\mathrm{s}}=1.0 \mathrm{MPa}$ and $\eta_{\mathrm{s}}=5 \%$. 
Furthermore, the assumption of $K_{H M}^{0}=K_{M H}^{0}$ holds true. The maximum deviation between $K_{H M}^{0}$ and $K_{M H}^{0}$ is $11 \%$ in the BE/FE model and only $3.3 \%$ for the FE model. In general, there is good agreement between the values of the impedance components computed by the $\mathrm{FE}$ and the $\mathrm{BE} / \mathrm{FE}$ models. As expected, all the stiffness components increase with the skirt lengths, cf. Table II. The magnitude of the sliding, rocking and coupling terms increases slightly with Poisson's ratio, $v_{\mathrm{s}}$. This is due to the fact that an increase in $v_{\mathrm{s}}$ for a fixed value of $G_{\mathrm{s}}$ implies an increase in Young's modulus, $E_{\mathrm{s}}=2 G_{\mathrm{s}}\left(1+v_{\mathrm{s}}\right)$.

\subsection{Dynamic stiffness-variation in Poisson's ratio}

The dynamic stiffness for different Poisson's ratios is presented in this section. The skirt length is fixed $(H / D=1)$, and the model properties are $G_{\mathrm{s}}=1.0 \mathrm{MPa}, \rho_{\mathrm{s}}=1000 \mathrm{~kg} / \mathrm{m}^{3}, \eta_{\mathrm{s}}=5 \%$, $E_{\mathrm{f}}=210 \mathrm{GPa}, v_{\mathrm{f}}=0.25, \eta_{\mathrm{f}}=2 \%$ and $t=50 \mathrm{~mm}$. In order to model a massless foundation $\rho_{\mathrm{f}}=0$ for the lid of the caisson and $\rho_{\mathrm{f}}=\rho_{\mathrm{s}}$ for the skirt. In Figures 7-9, the results are shown for five different values of Poisson's ratio and for the frequency range $\left.\left.a_{0} \in\right] 0 ; 6\right]$. Note that it is possible to solve the $\mathrm{BE}$ system for $v_{\mathrm{s}}=0.5$ by reordering the fundamental solution; however, here the range in Poisson's ratio is thought to cover fully drained $\left(v_{\mathrm{s}}=0.1-0.2\right)$ to undrained $\left(v_{\mathrm{s}}=0.495\right)$ conditions.
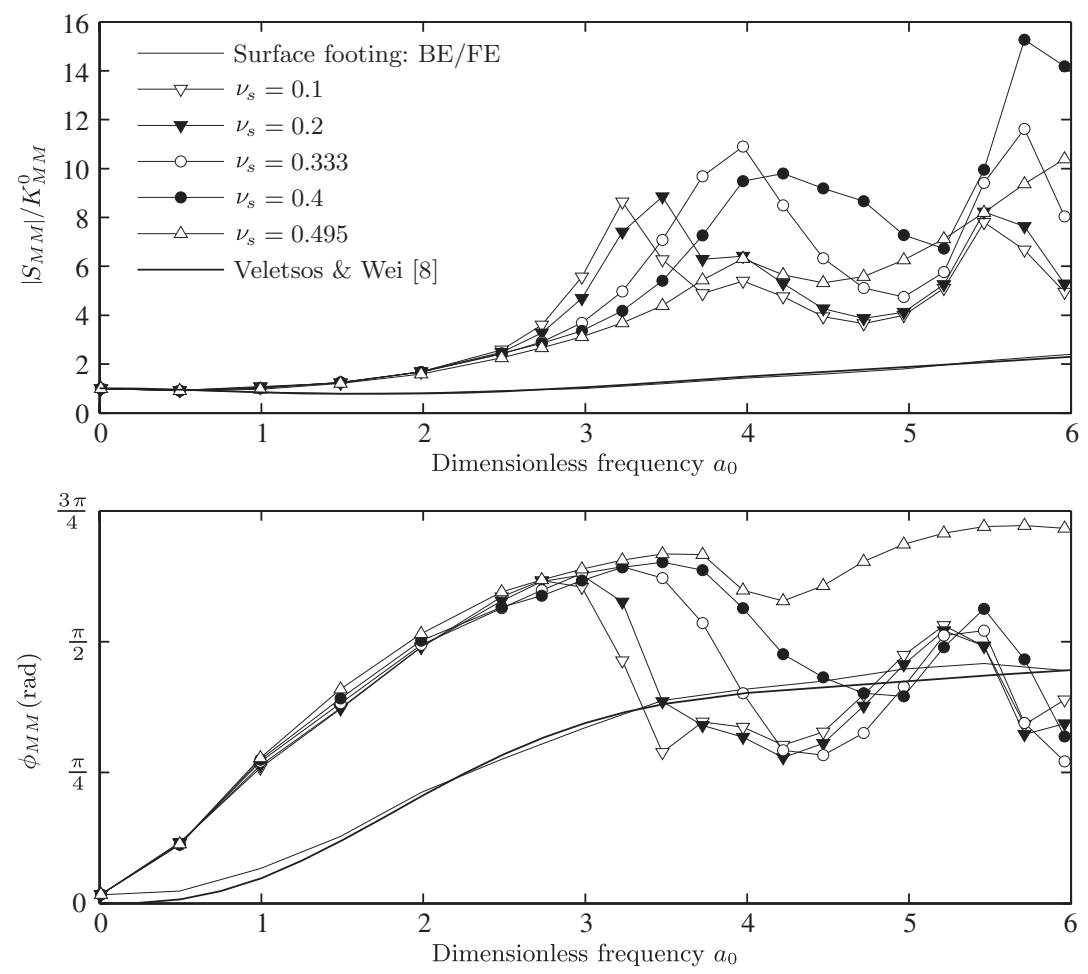

Figure 8. Rocking impedance: variation in Poisson's ratio. $G_{\mathrm{s}}=1.0 \mathrm{MPa}$ and $\eta_{\mathrm{s}}=5 \%$. 

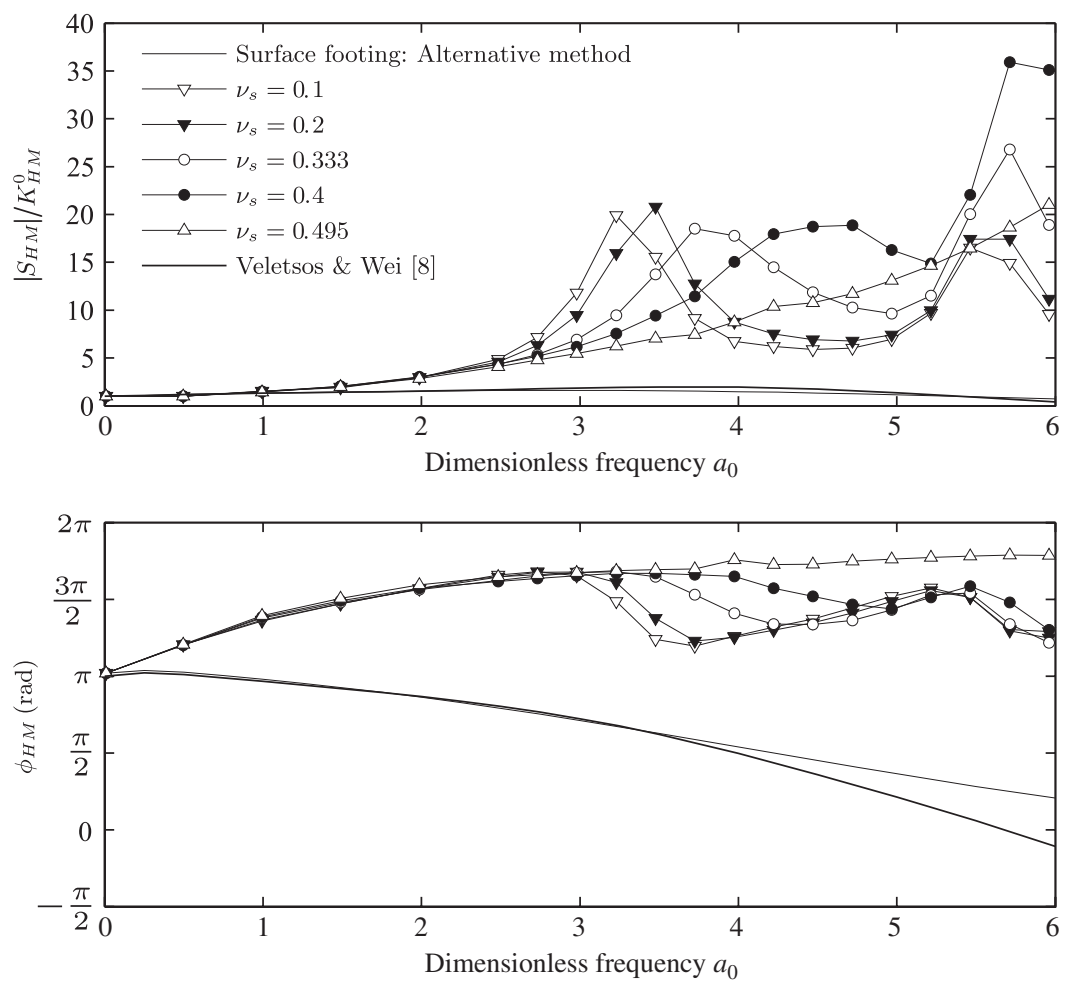

Figure 9. Coupling impedance: variation in Poisson's ratio. $G_{\mathrm{s}}=1.0 \mathrm{MPa}$ and $\eta_{\mathrm{s}}=5 \%$.

The analytical solution for a surface footing proposed by Veletsos and Wei [8] is included as a reference. Two numerical models of a massless surface footing are included for comparison with the analytical solution. The sliding and rocking impedances of the surface footing have been determined using a $\mathrm{BE} / \mathrm{FE}$ model. In the case of the coupling between horizontal sliding and rocking, numerical experiments indicate that convergence of the impedance cannot be established with a reasonably low number of degrees of freedom in the BE/FE model. In particular, it has been found that both the magnitude and the phase of the impedance are strongly dependent on the distance between the footing and the truncation edge of the free ground surface. Adaptive meshing could possibly improve the accuracy versus the number of degrees of freedom, but this facility is currently not available in the BE/FE software. Therefore, instead of the coupled BE/FE model based on Green's function for the full space, an alternative method proposed by Andersen and Clausen [41] has been applied. Here, the solution is established in the wavenumber domain, and the fundamental solution for a half-space is employed. Moreover, the impedance is computed directly by integration of the interaction forces between the footing and the subsoil. This is in contrast to the $\mathrm{BE} / \mathrm{FE}$ approach, in which the impedance is found by inversion of the dynamic flexibility matrix. The latter approach may involve great inaccuracies with respect to the coupling term since $\left|S_{H M}\right|$ is much smaller than $\left|S_{H H}\right|$ and $\left|S_{M M}\right|$ in particular in the high-frequency range.

The sliding and rocking impedances are clearly dependent on Poisson's ratio. The frequency at the first local extremum in the magnitude of the impedance in Figures 7 and 8 changes significantly 
with Poisson's ratio. The first peak for $v_{\mathrm{S}}=0.1$ occurs at $a_{0}=3.2$, whereas the first peak for $v_{\mathrm{S}}=0.4$ is placed close to $a_{0}=4.5$. However, the second local extremum is found at the frequency $a_{0}=5.5-5.7$ for all values of Poisson's ratio. This behaviour is explained by the fact that sliding and rocking impedances are governed by both shear wave propagation and compression wave propagation. More specifically, the first peak in the response corresponds to antiresonance of $P$-waves inside the caisson, whereas the second peak corresponds to antiresonance of $S$-waves. The latter is independent of Poisson's ratio, whereas an increase in $v_{\mathrm{s}}$ involves an increase in $c_{P}$. Hence, the first peak in Figures 7-9 occurs at lower frequencies for lower Poisson's ratios.

The coupling impedance in Figure 9 follows the pattern of the horizontal and moment impedances. Hence, an increase in the frequency provides an increase in the magnitude of the coupling impedance over the normalized frequency range $\left.\left.a_{0} \in\right] 0 ; 6\right]$. It is noted that the phase angle of the coupling impedance is close to $\pi$ radians for $a_{0}=0$ and slightly increases with the frequency in the range $\left.\left.a_{0} \in\right] 0 ; 6\right]$. Accordingly the static stiffness components $K_{H M}^{0}$ and $K_{M H}^{0}$ are negative, see Table II. It is generally observed that the coupling impedances of the suction caisson and the surface footing behave differently. Thus, in the case of the surface footing, a decrease in both the magnitude and the phase of the coupling impedance with the frequency is recorded in the interval $\left.\left.a_{0} \in\right] 0 ; 6\right]$.

A few remarks on the impedance of the surface footing: the sliding and rocking impedances determined using the BE/FE model agrees very well with the analytical solution reported by
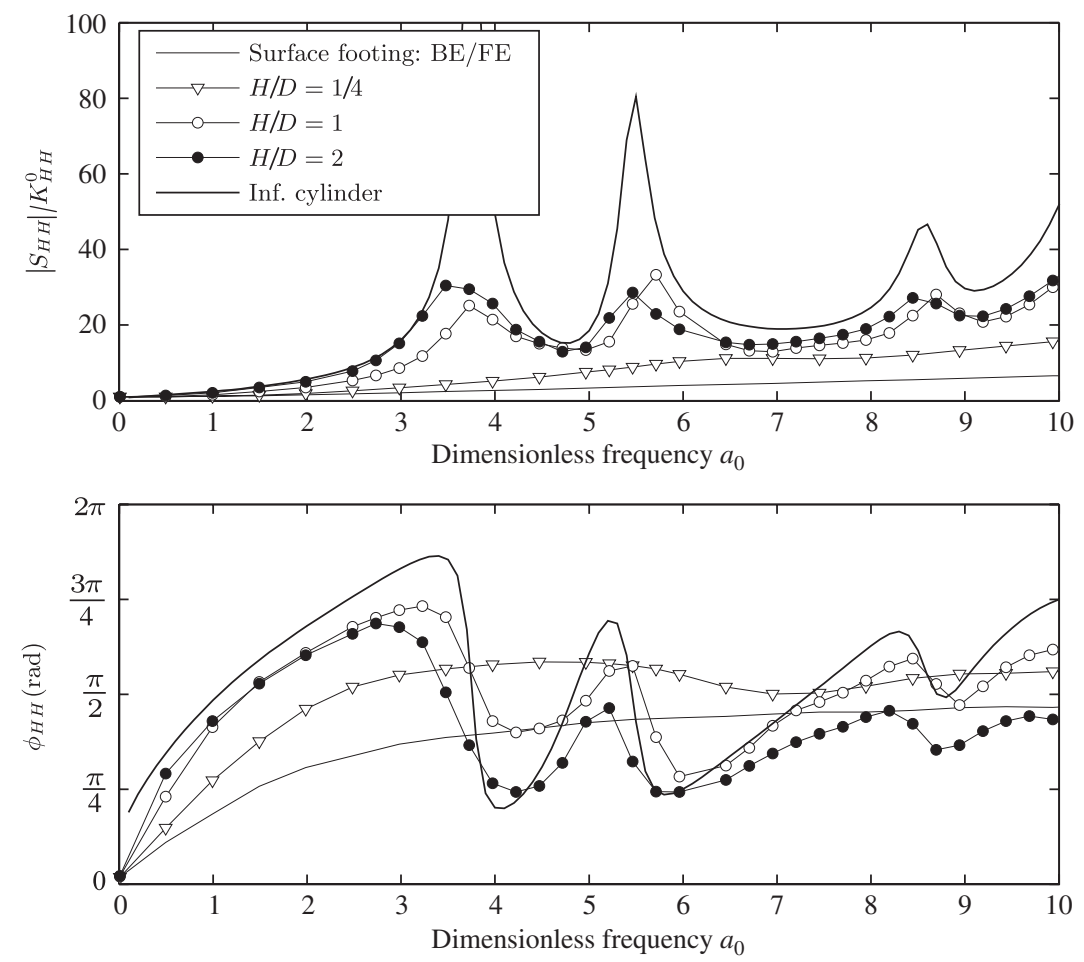

Figure 10. Sliding impedance: variation in the skirt length. $G_{\mathrm{s}}=1.0 \mathrm{MPa}, v_{\mathrm{s}}=\frac{1}{3}$ and $\eta_{\mathrm{s}}=5 \%$. 
Veletsos and Wei [8]. Furthermore, the coupling terms obtained using the alternative method [41] is consistent with the coupling reported by Veletsos and Wei. Note that the analytical solution with respect to the coupling term is an approximation, due to fact that the boundary conditions in the interface between the soil and the footing are partly relaxed. Finally, it is emphasized that the problem of determining the coupling between the horizontal sliding and rocking is encountered only for the surface footing. The coupling between the horizontal sliding and rocking for the suction caisson is described satisfactorily by the BE/FE model.

\subsection{Dynamic stiffness-variation in the skirt length}

The variation in the coupled dynamic stiffness components with respect to a change in the skirt length $H$ is presented in the following. The model properties are $G_{\mathrm{s}}=1 \mathrm{MPa}, v_{\mathrm{s}}=1 / 3$, $\rho_{\mathrm{s}}=1000 \mathrm{~kg} / \mathrm{m}^{3}, \eta_{\mathrm{s}}=5 \%, E_{\mathrm{f}}=210 \mathrm{GPa}, v_{\mathrm{f}}=0.25, \eta_{\mathrm{f}}=2 \%$ and $t=50 \mathrm{~mm}$. Again, $\rho_{\mathrm{f}}=0$ for the lid of the caisson and $\rho_{\mathrm{f}}=\rho_{\mathrm{s}}$ for the skirt in order to model a massless foundation.

The magnitudes and the phase angles of the impedance for $H / D=1 / 4,1$ and 2 are shown in Figures $10-12$ for the frequency range $\left.\left.a_{0} \in\right] 0 ; 10\right]$. The magnitudes are normalized with respect to the static stiffness coefficients listed in Table II, and the results achieved with two numerical models of a massless surface footing are included for comparison, see Section 6.3. In addition to this,
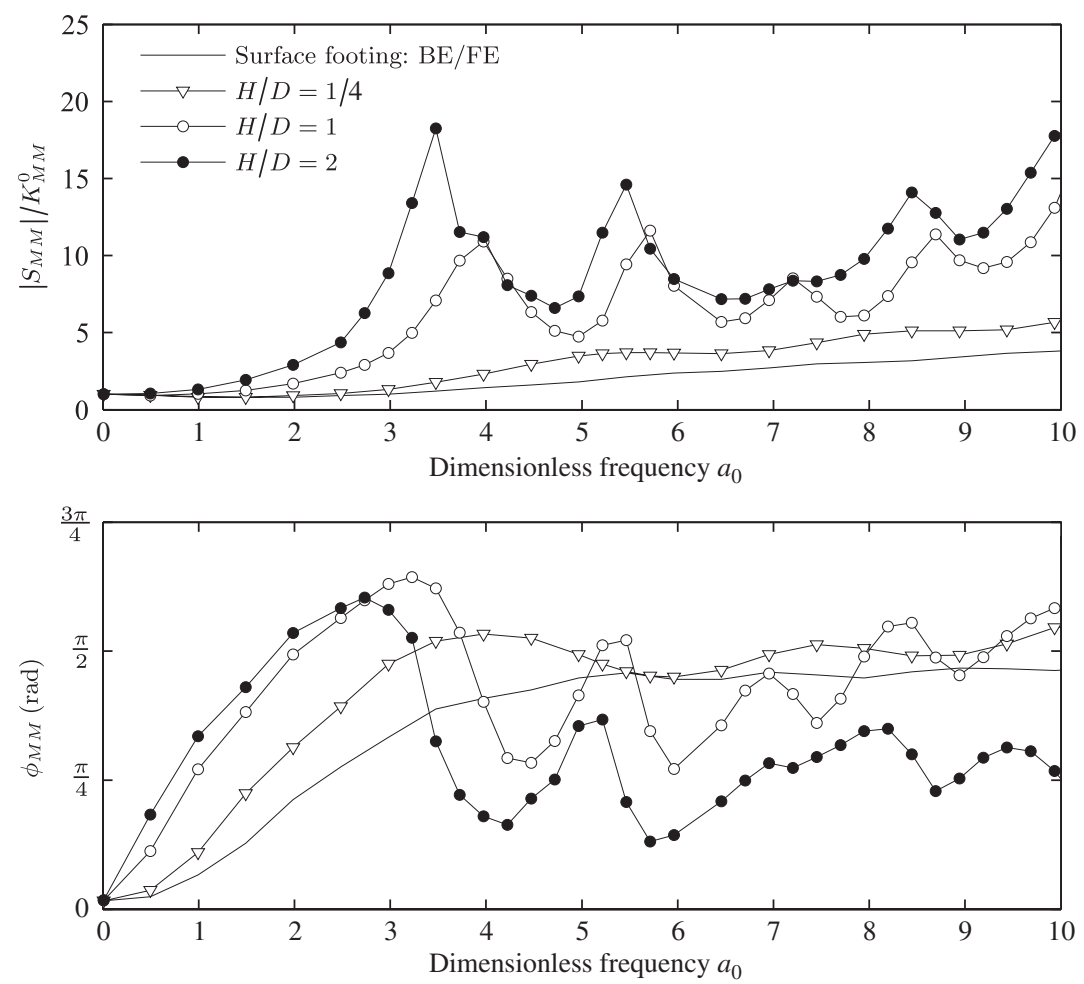

Figure 11. Rocking impedance: variation in the skirt length. $G_{\mathrm{s}}=1.0 \mathrm{MPa}, v_{\mathrm{s}}=\frac{1}{3}$ and $\eta_{\mathrm{s}}=5 \%$. 

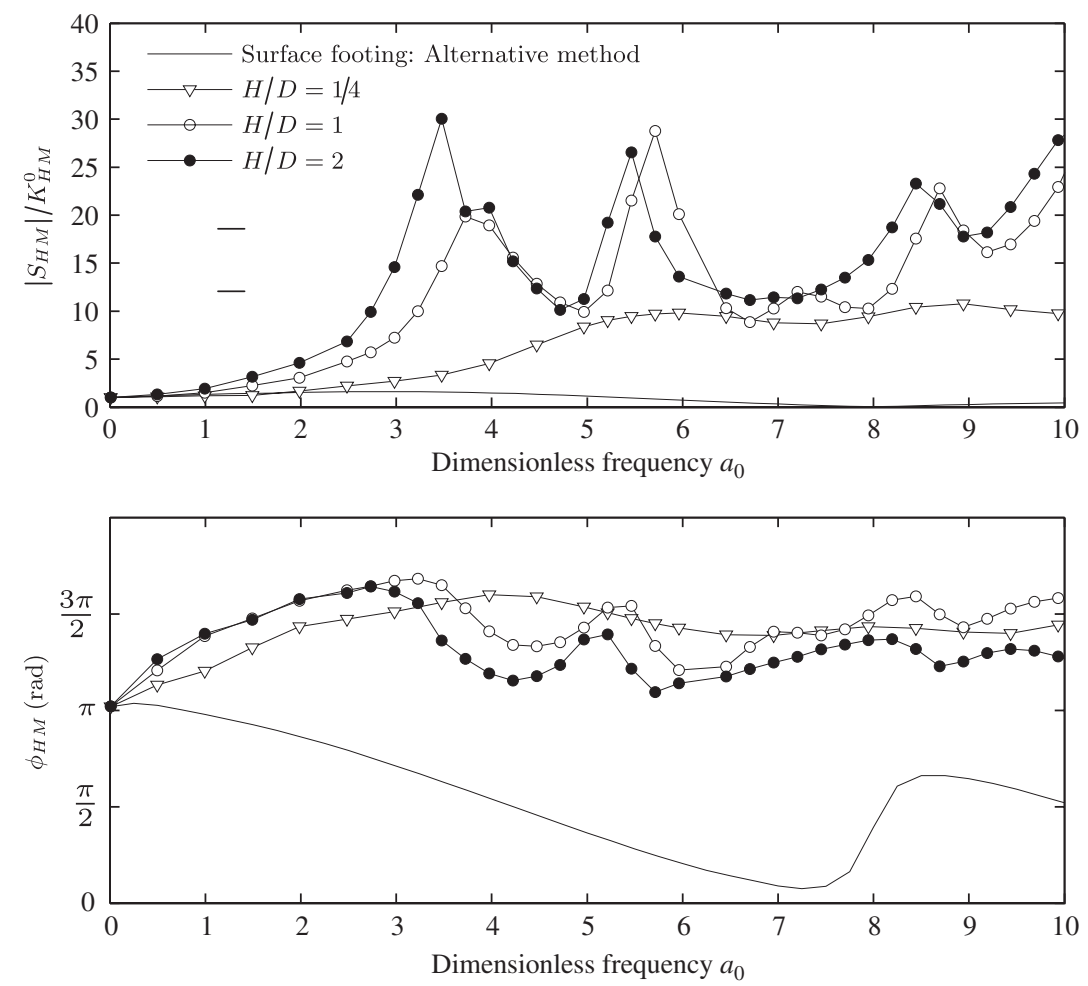

Figure 12. Coupling impedance: variation in the skirt length. $G_{\mathrm{s}}=1.0 \mathrm{MPa}, v_{\mathrm{s}}=\frac{1}{3}$ and $\eta_{\mathrm{s}}=5 \%$.

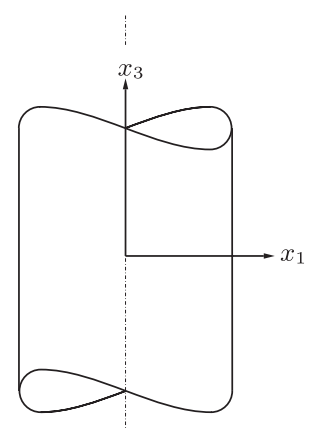

(a)

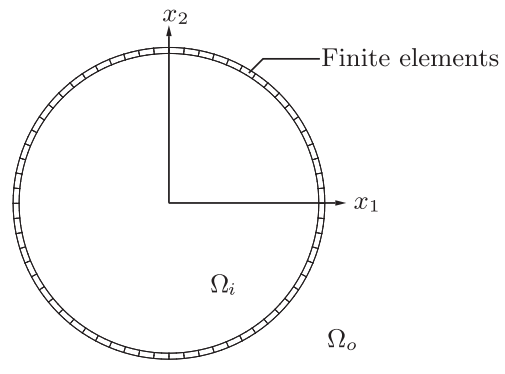

(b)

Figure 13. (a) Infinite hollow cylinder and (b) two-dimensional BE/FE model of the cylinder, where $\Omega_{\mathrm{i}}$ and $\Omega_{\mathrm{o}}$ are the inner and outer boundary element domains, respectively.

the horizontal sliding impedance of an infinitely long hollow cylinder $(H / D=\infty)$ has been computed by application of the two-dimensional BE/FE code TEA by Jones et al. [42]. The hollow cylinder is modelled with 64 quadrilateral finite elements employing quadratic interpolation. The 
interior and exterior soil domains are modelled with 64 boundary elements each. The model is sketched in Figure 13, and the plane strain is assumed. Evidently, a similar two-dimensional analysis cannot be performed for the rocking and coupling impedances. With reference to Figure 10, there is no indication of antiresonance of the waves inside the caisson with a relatively small embedment depth $(H / D=1 / 4)$, i.e. there are no local peaks in the normalized magnitude of the impedance component for sliding. Thus, the dynamic behaviour is similar to that of the surface footing, although the increase in the impedance with increasing frequency is more pronounced for the skirted foundation than for the surface footing. However, the sliding impedances for $H / D=1$ and 2 are characterized by a number of local tips and dips. The peaks are not repeated with the normalized frequency interval $\Delta a_{0}=\pi$. This is the case for the vertical and torsional impedances, where the location of the peaks is governed by the shear waves only. In contrast to this, the location of the peaks for the coupled sliding-rocking impedances is controlled by antiresonance of both shear waves and compression waves. Clearly, the locations of the peaks in the magnitude of the sliding impedance for $H / D=1$ and 2 correspond to those for the infinitely long cylinder. Similarly, the variation in the phase angle $\phi_{H H}$ is similar for $H / D=1,2$ and $\infty$, cf. Figure 10 . The magnitude of the horizontal impedance (Figure 10) seems to increase with the skirt length. However, the change from $H / D=1 / 4$ to 1 is significant, whereas only a small change is observed from $H / D=1$ to 2. The magnitude of the impedance for $H / D=2$ is actually below the impedance for $H / D=1$ at high frequencies. This behaviour suggests that the horizontal vibrations are transmitted to the surrounding soil at relatively shallow depths. Hence, the effects of increasing the skirt length diminish with depth. This is not the case for the moment impedance in Figure 11, where the effects of increasing the skirt length enlarge with depth. These tendencies are also evident in the static stiffness coefficients listed in Table II. Finally, the coupling impedance in Figure 12 increases moderately with an increase in the skirt length, and again the phase angle is close to $\pi$ radians for all frequencies. Otherwise, the overall response is similar to the horizontal and moment impedances.

\section{CONCLUSION}

The impedance of suction caissons with respect to vertical and coupled sliding-rocking vibrations has been analysed numerically, employing a three-dimensional coupled BE/FE model in the frequency domain.

\subsection{Vertical vibrations}

The dynamic stiffness has been investigated for several different combinations of the mechanical properties of the soil-foundation system, and the following observations can be made:

- The vertical dynamic stiffness changes with the skirt length. For a relatively small embedment depth $(H / D=1 / 4)$, the impedance varies smoothly with the frequency, whereas the impedance for $H / D=1$ and 2 is characterized by distinct peaks.

- The impedance for high values of $G_{\mathrm{s}}(1000 \mathrm{MPa})$ approaches the shape of the frequencydependent behaviour of the surface foundation. When $G_{\mathrm{s}}$ decreases, the local oscillations become more distinct and the influence of the skirt flexibility vanishes, i.e. the caisson reacts as a rigid foundation. Rigid behaviour can be assumed for $G_{\mathrm{s}} \leqslant 1.0 \mathrm{MPa}$. 
Furthermore, the high-frequency behaviour of the suction has been investigated. Here, the main conclusions are:

- Generally, the magnitude of the impedance increases with the skirt length.

- The normalized magnitude of the impedance is characterized by repeated oscillations with local extremes for $\left.\left.a_{0} \in\right] 0 ; 10\right]$. However, the average dynamic stiffness appears to be increasing monotonously with increasing frequency, similar to the situation for surface footing.

- The phase angle for the suction caissons oscillate around $\pi / 2$ for $a_{0}>4$, and it will eventually stabilize at higher frequencies.

The repeated oscillations in the impedance of the suction caisson are due to resonance and antiresonance of the soil inside the suction caisson. This is concluded by comparing the vertical impedance characteristics of the suction caisson with those of an infinite cylinder subjected to dynamic vertical excitation in the axial direction.

\subsection{Coupled sliding-rocking vibrations}

The impedance of the coupled sliding-rocking vibrations has been analysed with respect to the effects of Poisson's ratio and the skirt length. The following conclusions can be made:

- The static stiffness has been calculated using a BE/FE model and an FE model. The largest deviations of the results of the two models are 7.4, 7.2 and $16.8 \%$ for the sliding, rocking and coupling terms, respectively.

- The two coupling terms between sliding and rocking are equal, i.e. $K_{H M}^{0}=K_{M H}^{0}$, within the accuracy of the analysis. The maximum deviation between $K_{H M}^{0}$ and $K_{M H}^{0}$ is $11 \%$.

- The sliding and rocking impedances are clearly dependent on Poisson's ratio of the soil, and the local extremum in the magnitude of the impedance changes significantly with Poisson's ratio.

- The effects of increasing the skirt length diminish with depth with respect to the horizontal impedance. The effects of increasing the skirt length enlarge with depth with respect to the rocking impedance and the sliding-rocking coupling components.

- The coupled sliding-rocking impedances are characterized by a complex wave interference pattern in the soil inside the skirts. The local peaks in the magnitude of the impedance components are not repeated by $\Delta a_{0}=\pi$, which is the case for the vertical and torsional impedance components. The location of the peaks for the coupled sliding-rocking impedances is controlled by antiresonance of both shear waves and compression waves.

- The analysis of the horizontal impedance for an infinite hollow cylinder clearly shows the anti-resonance frequencies of both shear waves and compression waves for the vibrating cylinder. The results agree very well with the horizontal impedance of the suction caissons.

\section{REFERENCES}

1. Houlsby GT, Ibsen LB, Byrne BW. Suction caissons for wind turbines. Proceedings of International Symposium on Frontiers in Offshore Geotechnics: ISFOG 2005, Taylor \& Francis: London, 2005.

2. Senders M. Tripods with suction caissons as foundations for offshore wind turbines on sand. Proceedings of International Symposium on Frontiers in Offshore Geotechnics: ISFOG 2005, Taylor \& Francis: London, 2005.

3. Ibsen LB, Liingaard M, Nielsen SA. Bucket foundation, a status. Proceedings of Copenhagen Offshore Wind Conference and Exhibition, Copenhagen, 26-28 October 2005. 
4. Liingaard M. Dynamic behaviour of suction caissons. Ph.D. Thesis, Department of Civil Engineering, Aalborg University, 2006.

5. Andersen L, Jones CJC. BEASTS - a computer program for boundary element analysis of soil and threedimensional structures. ISVR Technical Memorandum 868, Institute of Sound and Vibration Research, University of Southampton, 2001.

6. Richart FE, Hall JR, Woods RD. Vibration of Soils and Foundations. Prentice-Hall: Englewood Cliffs, NJ, 1970.

7. Das BM. Principles of Soil Dynamics. Brooks/Cole: Pacific Grove, CA, U.S.A., 1993.

8. Veletsos AS, Wei YT. Lateral and rocking vibration of footings. Journal of the Soil Mechanics and Foundation Engineering Division (ASCE) 1971; 97:1227-1248.

9. Luco JE, Westmann RA. Dynamic response of circular footings. Journal of the Engineering Mechanics Division (ASCE) 1971; 97:1381-1395.

10. Krenk S, Schmidt H. Vibration of an elastic circular plate on an elastic half-space-a direct approach. Journal of Applied Mechanics 1981; 48:161-168.

11. Higdon RL. Radiation boundary conditions for elastic wave propagation. SIAM Journal on Numerical Analysis 1990; 27(4):831-870.

12. Higdon RL. Absorbing boundary conditions for acoustic and elastic waves in stratified media. Journal of Computational Physics 1992; 101:386-418.

13. Krenk S. Unified formulation of radiation conditions for the wave equation. International Journal for Numerical Methods in Engineering 2002; 53(2):275-295.

14. Wolf JP, Song C. Finite-element Modeling of Unbounded Media. Wiley: Chichester, England, 1996.

15. Andersen L. Wave propagation in infinite structures and media. Ph.D. Thesis, Structural Dynamics Group, Department of Civil Engineering, Aalborg University, 2002.

16. Pyl L, Clouteau D, Degrande G. A weakly singular boundary integral equation in elastodynamics for heterogeneous domains mitigating fictitious eigenfrequencies. Engineering Analysis with Boundary Elements 2004; 28: 1493-1513.

17. Domínguez J. Boundary Elements in Dynamics. Computational Mechanics Publications: Southampton, 1993.

18. Hall WS, Oliveto G (eds). Boundary Element Methods for Soil-Structure Interaction. Kluwer: Dordrecht, The Netherlands, 2003.

19. Beskos DE. Boundary element methods in dynamic analysis. Applied Mechanics Review 1987; 40:1-23.

20. Beskos DE. Boundary element methods in dynamic analysis: Part II (1986-1996). Applied Mechanics Review 1997; 50:149-197.

21. Veletsos AS, Tang Y. Vertical vibration of ring foundations. Earthquake Engineering and Structural Dynamics 1987; 15:1-21.

22. Veletsos AS, Damodaran Nair VV. Torsional vibration of viscoelastic foundations. Journal of Geotechnical Engineering Division (ASCE) 1974; 100:225-246.

23. Wong HL, Luco JE. Tables of impedance functions for square foundations on layered media. Soil Dynamics and Earthquake Engineering 1985; 4(2):64-81.

24. Mita A, Luco JE. Impedance functions and input motions for embedded square foundations. Journal of Geotechnical Engineering (ASCE) 1989; 115(4):491-503.

25. Emperador JM, Domínguez J. Dynamic response of axisymmetric embedded foundations. Earthquake Engineering and Structural Dynamics 1989; 18:1105-1117.

26. Novak M, Sachs K. Torsional and coupled vibrations of embedded footings. Earthquake Engineering and Structural Dynamics 1973; 2:11-33.

27. Avilés J, Pérez-Rocha LE. A simplified procedure for torsional impedance functions of embedded foundations in a soil layer. Computers and Geotechnics 1996; 19(2):97-115.

28. $\mathrm{Bu} \mathrm{S}$, Lin $\mathrm{CH}$. Coupled horizontal-rocking impedance functions for embedded square foundations at high frequency factors. Journal of Earthquake Engineering 1999; 3(4):561-587.

29. Andersen L, Jones CJC. Three-dimensional elastodynamic analysis using multiple boundary element domains. ISVR Technical Memorandum 867, Institute of Sound and Vibration Research, University of Southampton, 2001.

30. Andersen L, Jones CJC. Finite element addendum for BEASTS. ISVR Technical Memorandum 881, Institute of Sound and Vibration Research, University of Southampton, 2002.

31. Sheng X, Jones CJC, Petyt M. Ground vibration generated by a load moving along a railway track. Journal of Sound and Vibration 1999; 228(1):129-156.

32. Tullberg O, Bolteus L. A critical study of different boundary element stiffness matrices. In Boundary Element Methods in Engineering, Brebbia CA (ed.). Springer: Berlin, 1982; 625-635. 
33. Haas M, Kuhn G. Mixed-dimensional, symmetric coupling of FEM and BEM. Engineering Analysis with Boundary Elements 2003; 27:575-582.

34. Ganguly S, Layton JB, Balakrishna C. Symmetric coupling of multi-zone curved Galerkin boundary elements with finite elements in elasticity. International Journal for Numerical Methods in Engineering 2000; 48:633-654.

35. Ganguly S, Layton JB, Balakrishna C. A coupling of multi-zone curved Galerkin BEM with finite elements for independently modelled sub-domains with non-matching nodes in elasticity. International Journal for Numerical Methods in Engineering 2004; 59:1021-1038.

36. ABAQUS-Version 6.4 2003; ABAQUS, Inc. Pawtucket, RI, 2003.

37. Chen JT, Chen KH, Chen CT. Adaptive boundary element method of time-harmonic exterior acoustics problems in two dimensions. Computer Methods in Applied Mechanics and Engineering 2002; 191:3331-3345.

38. Doherty JP, Deeks AJ. Elastic response of circular footings embedded in a non-homogeneous half-space. Géotechnique 2003; 53(8):703-714.

39. Doherty JP, Houlsby GT, Deeks AJ. Stiffness of flexible caisson foundations embedded in non-homogeneous elastic soil. Journal of Geotechnical and Geoenvironmental Engineering (ASCE) 2005; 131(12):1498-1508.

40. Kitahara M. Applications of boundary integral equation methods to eigenvalue problems of elastodynamic and thin plates. Research Report, University of Kyoto, 1984.

41. Andersen L, Clausen J. Impedance of surface footings on layered ground. Computers and Structures 2007; DOI: $10.1016 /$ j.compstruc.2007.05.030.

42. Jones CJC, Thompson DJ, Petyt M. TEA - a suite of computer programs for elastodynamic analysis using coupled boundary elements and finite elements. ISVR Technical Memorandum 840, Institute of Sound and Vibration Research, University of Southampton, 1999. 